\title{
A ARQUEOLOGIA HISTÓRICA NO MUSEU PARAENSE EMÍLIO GOELDI ${ }^{1}$
}

The historical archaeology of paraense Emílio Goeldi museum

Helder Bruno Palheta Ângelo ${ }^{2}$

\section{RESUMO}

O texto apresenta um panorama da Arqueologia Histórica desenvolvida pelo Museu Paraense Emílio Goeldi. Campo de pesquisa que despontou na instituição a partir da década de 1980, foi consolidado através de estudos que trouxeram novos olhares sobre a história da Amazônia e vêm contribuindo para a preservação e valorização do patrimônio histórico e cultural da região. Destarte, será discutida a produção científica promovida pelo MPEG, abordando os principais temas de investigação e os resultados obtidos.

Palavras-chave: Arqueologia Histórica; Museu Paraense Emílio Goeldi; patrimônio histórico.

\begin{abstract}
The paper presents an overview of the Historical Archeology developed by the Paraense Emilio Goeldi Museum. This field of research that began to emerge in the institution in the 1980's was consolidated by studies that have brought new perspectives on the history of the Amazon and are contributing to the preservation and appreciation of the historical and cultural heritage of the region. Thus, the scientific production promoted by MPEG will be discussed, addressing the main research topics and results obtained.
\end{abstract}

Keywords: Historical Archaeology; Paraense Emilio Goeldi Museum; historic heritage.

\section{RESUMEN}

Este texto presenta un panorama de la Arqueología Histórica realizada en el Museo Paraense Emilio Goeldi. Esta área de estudios, cuyos inicios en esta institución datan de la década de 1980, se consolida en estudios que aportan nuevas perspectivas sobre la historia de la Amazonía y viene contribuyendo para la conservación y valorización del patrimonio histórico y cultural de la región. Se discute, de esta forma, la producción científica promovida por el MPEG, abordando los principales temas de investigación y los resultados obtenidos.

Palabras clave: Arqueología Histórica, Museo Paraense Emilio Goeldi, patrimonio histórico.

\footnotetext{
${ }^{1}$ Este artigo faz parte de uma pesquisa em andamento: "Teorias, correntes e personalidades da arqueologia na Amazônia", desenvolvida junto à Coordenação de Informação e Documentação (CID) do Museu Paraense Emílio Goeldi e financiada pelo CNPq. Agradeço a revisão do texto feita pela coordenadora Msc. Maria Astrogilda Ribeiro da Silva e o auxílio do arqueólogo Fernando Luiz Tavares Marques, responsável pela indicação de vários textos para a construção do artigo.

${ }^{2}$ Graduado em História pela Universidade Federal do Pará e mestre em História Social da Amazônia pela mesma instituição. Atualmente é bolsista na modalidade PCI-DD do Museu Paraense Emílio Goeldi. e-mail: helderangelo@,museu-goeldi.br; brunnoangelo@hotmail.com
} 


\section{Introdução}

Podemos considerar que a prática da arqueologia em terras amazônicas é indissociável da trajetória do Museu Paraense Emílio Goeldi. ${ }^{3}$ Muitas das informações que hoje possuímos sobre a pré-história da região se devem às pesquisas arqueológicas que foram promovidas pela instituição desde a segunda metade do século XIX, a partir da fundação da Sociedade Filomática do Pará (núcleo inicial do Museu Paraense) em 1866, cujos objetivos eram os estudos das ciências naturais, do ambiente e do homem amazônico (BARRETO, 1992; FERREIRA, 2010; SANJAD, 2010). A partir dessa iniciativa, enquanto se consolidava como um valoroso espaço da ciência, o Museu ministrava o processo de institucionalização e desenvolvimento da arqueologia (FERREIRA, 2010).

Nesse contexto, as ações de personalidades como Domingos Soares Ferreira Penna ${ }^{4}$, o suíço Emílio Goeldi ${ }^{5}$ e Aureliano de Pinto Guedes (auxiliar de Goeldi), foram fundamentais para o reconhecimento do potencial arqueológico da Amazônia. Fazer parte de expedições, realizar escavações, colher fragmentos relacionados à cultura indígena e formar coleções arqueológicas e etnográficas também tinham uma função definida. Segundo Nelson Sanjad:

Próximos da história e da etnologia, os debates arqueológicos desse período não podem ser dissociados do empenho de intelectuais e de governantes em prol da construção de uma identidade nacional. O passado pré-colonial e o presente aparecem, nesses debates, como um continuum na gênese da nação brasileira, sendo as várias etnias indígenas (e suas respectivas línguas, saberes, hábitos, mitos e cultura material), reunidas e homogeneizadas pelo conceito de "raça", identificadas como representantes legítimas da nacionalidade em tempos pretéritos. (SANJAD, 2011: 134)

As abordagens sobre as populações indígenas realizadas pelo Museu Paraense, nesse período, definiam fronteiras e estavam atreladas ao ideário de nação em voga. Um projeto de identidade nacional e geopolítico (FERREIRA, 2010).

No decorrer do século XX, os estudos arqueológicos correspondentes à pré-história da Amazônia continuaram em destaque na instituição. Pode-se considerar, por exemplo, as

\footnotetext{
${ }^{3}$ A denominação "Museu Paraense" foi dada em 1871. Em 1894, mudou para "Museu Paraense de História Natural e Etnografia". Já em 1900, mudou novamente, desta vez para "Museu Goeldi”. Por fim, em 1931, recebeu a denominação atual.

${ }^{4}$ Domingos Soares Ferreira Penna (1818-1888) foi o fundador do Museu Paraense em 1866 e primeiro diretor do instituto, atuando ainda como naturalista-viajante do Museu Nacional entre 1872-1884. Ele efetuou pesquisas arqueológicas na Ilha do Marajó (PA), nos rios Tocantins, Xingu, Amazonas, Maracá (no atual estado do Amapá), além de estudar os sambaquis existentes no litoral paraense (BARRETO, 1992).

${ }^{5}$ O zoólogo suíço Emílio Augusto Goeldi (1859-1917), assumiu a direção do Museu entre 1894 e 1907 , a convite do governador do Pará, Lauro Sodré, sendo responsável por constituir um plano sistemático de escavações e organizar as coleções arqueológicas e etnográficas da instituição (FERREIRA, 2009).
} 
pesquisas efetuadas pelos alemães Curt Nimuendaju e Protásio Frikel, os trabalhos desenvolvidos pelo casal Betty Meggers e Clifford Evans, cujas ideias e métodos de pesquisa influenciaram arqueólogos como o carioca Mário Ferreira Simões, o qual, a partir da década de 1960, organizou e estruturou um moderno setor de arqueologia no Museu. Não podemos esquecer-nos das pesquisas promovidas pela arqueóloga estadunidense Anna Roosevelt que, entre outras questões, refutaram as teorias de sua compatriota, Betty Meggers ${ }^{6}$.

Nos últimos anos, na Área de Arqueologia do Museu Emílio Goeldi, embora a chamada arqueologia pré-histórica ainda tenha destaque na produção científica da instituição, deve-se ressaltar a firmação das pesquisas de Arqueologia Histórica, iniciadas na década de 1980, incrementadas na década de 1990 e, atualmente, consolidadas com uma série de projetos de pesquisa, dissertações e teses de doutorado, além de diversos artigos científicos que propiciaram novos olhares sobre a história da Amazônia (PEREIRA, 2009).

Nesse sentido, o presente texto realiza um balanço sobre a arqueologia histórica promovida pelo Museu Paraense Emílio Goeldi, assunto que foi brevemente abordado por autores que escreveram sobre a história das pesquisas arqueológicas na instituição, como Barreto (1992) e Pereira (2009).

Antes, acreditando que a "Arqueologia só pode ser entendida em seu contexto histórico e social" (FUNARI, 2005: 1), creio ser necessário, primeiramente, fazer alguns apontamentos sobre o processo de nascimento da Arqueologia Histórica e as correntes teóricas que deram embasamento ao seu desenvolvimento, para assim melhor compreendermos o seu florescimento no Museu.

\footnotetext{
${ }^{6}$ Alicerçados nas ideias de determinismo ecológico e difusão cultural, Betty Meggers e Clifford Evans, em fins da década de 1940, deram início às pesquisas arqueológicas na região da foz do Rio Amazonas, mais especificamente nas ilhas do Marajó, Mexiana e Caviana. Com os resultados obtidos pela análise do material coletado, puderam identificar cinco fases culturais em sequência: Ananatuba, Mangueira, Formiga, Marajoara e Aruã, sendo que a fase Marajoara diferenciava-se das outras por não apresentar um padrão de cultura de "floresta tropical", sendo detentora de uma estrutura socioeconômica e tecnológica mais desenvolvida, observada a partir da presença de cerâmicas altamente elaboradas e aterros artificiais. Nesse sentido, a fase Marajoara corresponderia a uma cultura intrusa na dita área, uma anomalia, oriunda de um ambiente externo, provavelmente dos Andes. Contudo, com o passar do tempo, essa dita cultura não teria suportado as condições impostas pela floresta tropical, não havendo condições para a manutenção dos seus sistemas social, econômico e político. Como resultado, ela entrou em decadência, passando de uma organização política do tipo "cacicado" para "tribo de floresta tropical", a partir de uma perspectiva evolucionista então em voga na antropologia dos Estados Unidos. (MEGGERS \& EVANS, 1957; BARRETO, 1992; GUAPINDAIA, 2008) A partir da década de 1980, a arqueóloga Anna Roosevelt irá tecer críticas às teorias de Meggers, afirmando que a hipótese desta não se sustenta, pois as terras baixas teriam prioridade cronológica sobre as áreas montanhosas tanto no desenvolvimento de cerâmicas, quanto em ocupações sedentárias. Nesse sentido, em outra perspectiva, defende que as influências provenientes da floresta tropical contribuíram para o desenvolvimento da agricultura e cultura dos Andes. Para Roosevelt, o meio ambiente amazônico, rico em nutrientes, apresentava-se como extremamente favorável ao desenvolvimento humano, havendo a presença de sociedades hierárquicas do tipo "cacicado", sendo estas autóctones, provenientes diretamente de culturas ceramistas anteriores da Amazônia oriental, sem ligação com a região andina. Nesse sentido, a floresta tropical seria fonte de inovação e difusão de cultura. (ROOSEVELT, 1992; GUAPINDAIA, 2008)
} 


\section{Trajetória, correntes teóricas e definições: breves considerações.}

A arqueologia, mais especificamente a arqueologia responsável pelo estudo da préhistória, já se desenvolvia e atravessava um processo de institucionalização no Brasil desde a virada do século XIX para o XX, a partir das pesquisas empreendidas no Museu Botânico do Amazonas, no Museu Paraense e no Museu Paulista. (FERREIRA, 2010)

Por outro lado, a Arqueologia Histórica é uma modalidade relativamente ainda jovem. Denominação que surgiu nos Estados Unidos, ela foi consolidada no dito país na década de 1960, no contexto de florescimento da New Archaeology (ou Arqueologia Processual) (FUNARI, 2005; JOHNSON, 2000). De modo geral, tal corrente teórica surgiu do sentimento de insatisfação com a situação da arqueologia até aquele contexto ${ }^{7}$ e veio com o intuito de fazer uma mudança na disciplina científica. Era preciso centrar as atenções menos nos objetos e nas suas descrições. Os arqueólogos que seguiram essa linha buscavam "ser mais científicos e mais antropológicos" (JOHNSON, 2000: 38). Não à toa, um dos líderes dessa geração, Lewis Binford, defendia uma visão da arqueologia como antropologia (BINFORD, 1962). Pretendia-se encontrar regularidades no comportamento humano ou, melhor explicando, leis transculturais de comportamento (FUNARI, 2005).

Foi nesse momento que um grupo de arqueólogos estadunidenses tentou adaptar as ideias da New Archaeology para o estudo arqueológico dos períodos históricos (JOHNSON, 2000). De acordo com Binford (1967 apud JOHNSON, 2000: 192), “os especialistas nesse campo deveriam utilizar os métodos de contestação e avaliação que são habituais entre os arqueólogos da pré-história”.

Nas décadas de 1980/90, assim como aconteceu em outras ciências sociais, a arqueologia sofreu a interferência do pós-processualismo. Corrente teórica que surgiu como uma alternativa à New Archaeology, ela volta suas atenções, entre outras questões, para os estudos do poder social, da ideologia e de gênero (COSTA, 2010), sendo que os objetos deveriam ser vistos como elementos ativos, utilizados para reproduzir relações sociais, atentando para o significado cultural que a cultura material possuía para uma determinada sociedade (REIS, 2002; SYMANSKI, 2009). Ideia que também interessou os arqueólogos históricos por dar privilégio ao significado cultural adquirido pela cultura material que

\footnotetext{
${ }^{7}$ Principalmente em relação à arqueologia histórico-cultural que, por influência do evolucionismo cultural que a antecedeu, enquadrava os achados arqueológicos nos modelos deste último, havendo a preocupação dos arqueólogos no estudo da distribuição geográfica dos artefatos e suas relações com os grupos históricos, nas sequências regionais documentadas pelos artefatos e nos atributos técnicos destes e na explicação das mudanças culturais relacionadas a causas externas (REIS, 2002).
} 
determinada sociedade produziu e utilizou, retomando para a Arqueologia a discussão de problemas de caráter histórico ligados às propostas da Nova História Francesa ${ }^{8}$.

No Brasil, as primeiras pesquisas sistemáticas em Arqueologia Histórica surgiram, embora timidamente, na década de 1960 a partir de investigações promovidas por profissionais que tinham experiências nas temáticas inerentes à pré-história, principalmente relacionados ao PRONAPA (Programa Nacional de Pesquisas Arqueológicas) ${ }^{9}$, mantido pelo Smithsonian Institute ${ }^{10}$. Não à toa, esses arqueólogos utilizavam os princípios teóricos e metodológicos correspondentes à abordagem histórico-cultural (SYMANSKI, 2009).

Sua prática tem sido ampliada no cenário brasileiro a partir da década de 1980, principalmente após a restauração paulatina das liberdades políticas, com o fim do arbítrio, com o relaxamento da censura e com a passagem para um regime civil em 1985 (FUNARI 2005). Foi quando a Arqueologia Histórica finalmente cristalizou-se como uma importante ferramenta para a compreensão do passado brasileiro e foram abertas novas perspectivas com objetivos de darem voz a minorias étnicas e grupos subalternos, oprimidos, cujas ações não são explícitas em documentos oficiais; resgatar práticas cotidianas sobre as quais normalmente não se escreve; recuperar memórias e assim por diante (LIMA, 2003).

Campo científico relativamente jovem, não causaria tanta surpresa a dificuldade existente ainda hoje em atribuir um conceito fixo à Arqueologia Histórica. De fato, tentar defini-la não é uma das tarefas mais fáceis, em virtude dos vários debates teóricometodológicos pelos quais passou durante sua trajetória.

Algumas definições inerentes à Arqueologia Histórica já foram bastante utilizadas por estudiosos da área. Arqueologia Histórica é o "estudo dos remanescentes históricos de qualquer período histórico", escreveu Robert Shcuyler (apud LIMA, 1993) na década de 1970. Para Orser Jr. (1992: 23) trata-se do "estudo arqueológico dos aspectos materiais, em termos históricos, culturais e sociais concretos, dos efeitos do mercantilismo e do capitalismo que foi trazido da Europa em fins do século XV e que continua em ação ainda hoje". Perspectiva que é compartilhada também por Hall e Silliman (2006). Não menos usual é a

\footnotetext{
${ }^{8}$ Para uma discussão mais aprofundada sobre a Nova História Francesa, ver BURKE (1997).

${ }^{9}$ Realizado entre 1965 e 1970, com a colaboração do IPHAN e CNPq, sendo conveniado ao Smithsonian Institution, tinha por objetivo estabelecer a primeira sequência das culturas indígenas dos estados litorâneos brasileiros desde o Pará até o Rio Grande do Sul, com acento especial nas migrações dos grupos Tupi- Guarani. Teve como mentores o casal Betty Meggers e Clifford Evans.

${ }^{10} \mathrm{O}$ Smithsonian Institute, com sede em Washington, nos Estados Unidos, vem realizando ações na Amazônia desde o século XIX. Em meados do século XX ele financiou programas de arqueologia no Brasil, patrocinando ainda, por exemplo, as pesquisas realizadas pelo casal Betty Meggers e Clifford Evans, atreladas ao MPEG (BARRETO, 1992).
} 
definição de Deetz (1997), como sendo “A arqueologia da disseminação da cultura europeia através do mundo desde o século XV e seu impacto nas populações indígenas".

Para Funari (1996: 164), “a definição exata de Arqueologia Histórica constitui, provavelmente, a questão mais controversa na atualidade." A compreensão dela como o estudo arqueológico do período posterior à chegada dos europeus no continente americano é comumente colocada em xeque. Os modelos adotados pelos arqueólogos estadunidenses partem do pressuposto, talvez válido nos Estados Unidos, de que as relações sociais foram marcadas pelo domínio do capital. Já no contexto brasileiro, onde predominavam as sociabilidades muitas vezes distantes desse ideal capitalista e mais próximas do patriarcalismo escravista, os modelos importados (dos Estados Unidos) nem sempre dão conta da diversidade social brasileira (FUNARI, 2003).

Por outro lado, ao entender esse campo científico como o estudo da expansão da cultura européia por todo o mundo, corre-se o risco de dar conta de apenas um lado da moeda, "pois continuidades milenares podem ser tão ou mais importantes que a europeização do globo" (FUNARI, 1996: 166). A civilização "capitalista" não foi capaz de reduzir todas as relações sociais do mundo a relações econômicas (FUNARI, 2007) ${ }^{11}$.

Dessa forma, buscando contornar tal problemática, Funari afirma que o objeto de estudo da Arqueologia Histórica passa a ser justamente a "interação entre dominantes e dominados, letrados e iletrados, em diferentes contextos culturais e cronológicos." (FUNARI, 1996: 166). A partir dela, observamos os contatos multiculturais e as contradições das sociedades pretéritas, as tensões sociais que podem ser interpretadas tanto nos documentos históricos quanto nos vestígios materiais (COSTA, 2010).

\section{A Arqueologia Histórica em terras brasileiras: balanços bibliográficos}

Diante do florescimento das pesquisas em Arqueologia Histórica no Brasil, duas produções realizaram uma revisão intensa sobre os trabalhos efetivados no país.

O primeiro trabalho diz respeito a um artigo publicado por Tânia Andrade Lima em 1993, intitulado “Arqueologia Histórica no Brasil: balanço bibliográfico (1960-1991)”. A autora ressalta que no seu início, na década de 1960, os primeiros trabalhos sistemáticos concentraram-se no eixo sul/nordeste, enquanto que as outras regiões do país, como no norte,

\footnotetext{
${ }^{11}$ A priorização do capitalismo como algo incontrolável, domando as mentes dos grupos subordinados, pode levar a uma subavaliação da resistência e da heterogeneidade ocorrida em diversos contextos históricos (FUNARI, 2007).
} 
centro-oeste e mesmo o sudeste estavam distante dos debates. Era um momento em que disciplina sofria com o pequeno número de profissionais em ação e até mesmo com certo preconceito, recebendo em reuniões científicas um tratamento depreciativo (LIMA, 1993).

No entanto, a partir da década de 1980, surge um novo panorama, com o fortalecimento da subdisciplina a partir de uma maior coesão entre os especialistas, havendo o aumento da troca de informações, a formação de grupos de trabalhos e a promoção de novos encontros. Também é observado o florescimento de trabalhos mais comprometidos com a teoria, com abordagens processuais, trazendo à tona aspectos políticos, ideológicos e simbólicos (LIMA, 1993).

Por fim, em seu artigo, a autora faz uma listagem da bibliografia da Arqueologia Histórica brasileira correspondente ao período 1969-1991. São relacionados oitenta e dois trabalhos realizados em estados como Pernambuco, Rio Grande do Norte, Rio de Janeiro, São Paulo, Rio Grande do Sul, Bahia, Espírito Santo, Paraná, Goiás, Minas Gerais, além de artigos que tratam de teoria e método em Arqueologia Histórica. (LIMA, 1993). Contudo, mesmo diante deste considerável levantamento, não há menção às pesquisas em arqueologia histórica na Amazônia.

Luís Cláudio Pereira Symanski também buscou realizar um balanço da subdisciplina no país, enfocando o período posterior à análise feita por Lima (1993). Em seu “Arqueologia Histórica no Brasil: uma revisão dos últimos vinte anos", publicado em 2009, Symanski realiza uma abordagem sobre os caminhos que ela tomou na década de 1990 e início do século XXI.

Uma das questões discutidas pelo autor diz respeito ao cenário atual da Arqueologia Histórica no país, caracterizado pela continuidade da abordagem histórico-cultural; aplicação de métodos e conceitos da arqueologia processual; reprodução da abordagem históricocultural, porém sob o novo rótulo de abordagem contextual; e por abordagens críticas e simbólicas, explorando uma diversidade de temáticas relacionadas ao processo de expansão do capitalismo (SYMANSKI, 2009).

Outro ponto trabalhado por Symanski corresponde à intensa bibliografia por ele levantada. Desse modo, são apresentadas, por exemplo, as pesquisas feitas em estados como Rio Grande do Sul, São Paulo, Rio de Janeiro, Paraná, Bahia, Pernambuco, Minas Gerais, Mato Grosso e Alagoas. Porém, apesar desse intenso levantamento, que contempla as regiões 
sul, sudeste, nordeste e centro-oeste, não há, também, referências à Arqueologia Histórica praticada na Amazônia brasileira. ${ }^{12}$

Dessa forma e diante dos exemplos que foram expostos, propõe-se fazer uma reflexão sobre a prática da Arqueologia Histórica na Amazônia, mais especificamente a promovida pelo Museu Paraense Emílio Goeldi, destacando o que as pesquisas têm proporcionado para um maior conhecimento sobre a história da região.

\section{A Arqueologia Histórica no Museu Paraense Emílio Goeldi: objetos e resultados}

No Museu Paraense Emílio Goeldi, as primeiras pesquisas relacionadas à Arqueologia Histórica acompanharam o contexto nacional e datam da década de 1980.

Embora a instituição tenha realizado a primeira experiência nesse campo em $1985^{13}$, o primeiro projeto sistemático que apresentou resultados foi promovido por Scott Anderson e Fernando Marques nas localidades interioranas de Igarapé-Miri e Barcarena ${ }^{14}$, em 1988 e 1989, respectivamente, quando se fez o levantamento dos antigos engenhos movidos pela maré na região (BARRETO, 1992). Visando as comunidades locais, tal projeto pretendia fazer um resgate da tradicional tecnologia de captura da energia de antigos engenhos movidos à maré, adaptando-a, com o uso de micro-turbinas, como alternativa para o desenvolvimento rural (ANDERSON, MARQUES \& NOGUEIRA, 1993).

De certo modo, as incursões que o Museu Emílio Goeldi promoveu na área de Arqueologia Histórica se deram tardiamente. Na década de 1980, enquanto outras regiões do país já possuíam uma trajetória em pesquisas sistemáticas, os trabalhos em Arqueologia Histórica na instituição eram escassos, havendo prioridades, por parte dos pesquisadores, de estudos relacionados à tradicional arqueologia pré-histórica.

Tal cenário irá ser alterado na década de 1990, quando há o incremento da Arqueologia Histórica a partir de projetos de pesquisas, dissertações de mestrado, teses de doutorado e a publicação de artigos científicos (PEREIRA, 2009).

Manteve-se a atenção destinada ao empreendimento canavieiro na Amazônia. Em 1992 foi publicado no Boletim do Museu Paraense Emílio Goeldi os resultados da pesquisa

\footnotetext{
12 É pertinentes ressaltar que, embora não tivessem como principal objetivo, outros trabalhos realizaram um levantamento sobre a arqueologia histórica no país, como no caso de Costa (2010) e Funari (1997). Nestes, contudo, prevalece ainda a ênfase dada à sua prática em regiões nordeste, sul e sudeste, enquanto que a região amazônica permanece distante de suas análises.

${ }^{13}$ No final de 1985, quando Fernando Marques, Vera Guapindaia e Edithe Pereira realizaram um levantamento arqueológico e histórico em uma residência localizada em Soure (PA).

${ }^{14}$ Igarapé-Miri e Barcarena estão localizadas na chamada "zona estuarina amazônica", sendo que a primeira está localizada a cerca de $80 \mathrm{~km}$ de Belém, enquanto que Barcarena a $22 \mathrm{~km}$ da capital paraense.
} 
promovida por Scott Anderson e Fernando Marques na localidade de Igarapé-Miri, sendo estudados os vestígios de treze antigos engenhos de cana-de-açúcar movidos à maré, suas técnicas de instalação e o seu modo de funcionamento. A relação da arqueologia com as comunidades locais esteve mais uma vez presente, já que muitas das informações obtidas foram oriundas das informações de moradores da região, concluindo-se que aquela tecnologia comumente era usada na região e obteve grande êxito (ANDERSON \& MARQUES, 1992).

No decorrer dos anos, as possibilidades de investigação floresceram. A contribuição da disciplina para o entendimento da história amazônica também pode ser verificada na tese de Fernando Marques, que trouxe à discussão a história da agroindústria canavieira no estuário amazônico ${ }^{15}$. Mesclando disciplinas como história, arqueologia e arquitetura, os estudos sobre a cultura material inerente aos engenhos Murutucu, Jaguarari, Uriboca e Mocajuba promoveram uma análise sobre o ambiente, as características arquitetônicas e o comércio da região durante os séculos XVIII e XIX. Destaque para uma das especificidades da produção canavieira relacionada à grande quantidade de rios, furos e igarapés que viabilizaram a uma série de indivíduos a instalação de engenhos, desde os mais simples, até aos mais pomposos (MARQUES, 2004) ${ }^{16}$.

No Museu Paraense Emílio Goeldi, a importância que o estudo dos engenhos amazônicos adquiriu viabilizou o surgimento, nos anos 2000, do projeto "Arqueologia e história de engenhos coloniais no estuário amazônico" ${ }^{17}$, dando continuidade às pesquisas iniciadas na década de 1980 e revelando a diversidade da cultura material presente em tais empreendimentos. A recorrência de cerâmicas indígenas e neobrasileiras, objetos de vidro e metal e louças de procedência europeia, por exemplo, permite pensá-los como cenários em que os contatos entre culturas distintas eram frequentes.

\footnotetext{
${ }^{15}$ A chamada "zona estuarina amazônica" é caracterizada pela confluência da Baía do Guajará com os rios Mojú, Acará e Guamá, com o terreno marcado por regiões de várzea. Estas áreas próximas a rios caracterizam-se pela alta fertilidade do solo, contribuindo para a presença de um sistema agroindustrial que visava o beneficiamento da cana-de-açúcar principalmente através dos engenhos movidos à maré, bastante difundidos na região. Cf.: Anderson (1992) Sobre os engenhos e a história do empreendimento canavieiro na região ver também Marques (2003).

${ }^{16}$ Para a efetivação do seu trabalho, o autor não considerou somente uma corrente teórica arqueológica, mas sim, privilegiou pela mescla das abordagens histórico-cultural, processual e pós- processual, já que o estudo perpassou pela investigação das propriedades físicas dos artefatos e estruturas, buscando compreender sua funcionalidade e procedência cultural. Por outro lado, ao analisar a adaptação de tal modelo industrial às especificidades do meio físico regional, buscou-se também a fundamentação na Arqueologia Processual, dandose ênfase ainda aos grupos sociais que habitaram os engenhos. Por fim, relacionando-se à corrente pósprocessual, levou-se em conta a dimensão dos significados simbólicos, seus usos como demarcadores sociais e os aspectos simbólicos das sociedades que os produziram (MARQUES, 2004). Dessa forma, tal produção aproxima-se do crescente pluralismo presente na Arqueologia a partir da década de 1990, com a convivência de diferentes correntes teóricas como uma salutar característica da disciplina na atualidade (FUNARI, 2005).

${ }^{17}$ Coordenado pelo arqueólogo Fernando Luiz Tavares Marques.
} 
O desafio de pensar sobre a Arqueologia Histórica goeldiana não pode estar desvinculado da chamada Arqueologia de Salvamento, modalidade que foi sendo cada vez mais requisitada na medida em que cresciam na Amazônia os projetos desenvolvimentistas (hidrelétricas, exploração mineral, rodovias etc.), principalmente a partir da década de 1970 (BARRETO, 1992; PEREIRA, 2009). Já nos anos 2000, por exemplo, dois dos engenhos pesquisados por Marques (2004) - Jaguarari e Uriboca - tiveram que receber uma maior atenção, por estarem condicionados a sofrerem com os impactos da construção da rodovia Alça Viária ${ }^{18}$.

A associação das arqueologias históricas e de salvamento também esteve presente quando da implantação do "Programa de Arqueologia Preventiva na Área de Influência da Mina de Bauxita Paragominas"19 que visou a proteção de sítios arqueológicos pré-históricos e históricos, localizados em área de influência de exploração mineral nos municípios de Abaetetuba, Barcarena e Moju ${ }^{20}$ (CANTO \& LOPES, 2009).

Acompanhando esse panorama, muitas das produções têm enfatizado a relação com as comunidades estabelecidas próximas às áreas investigadas. Desse modo, esses grupos têm, através de ações de educação patrimonial, a oportunidade de reconhecerem a importância dos estudos realizados em igrejas e engenhos datados do período colonial, havendo, por conseguinte, uma maior preservação dos vestígios materiais e valorização da memória e da cultura local (MARQUES, 2003; CANTO \& LOPES, 2009; PEREIRA, 2009).

Se a arqueologia industrial tem sido de grande importância para a história da agroindústria canavieira na região, a arqueologia urbana também ganhou a atenção das pesquisas do Museu Paraense Emílio Goeldi nos últimos anos. Destaque para o centro histórico de Belém e outros espaços tradicionais que apresentam um valioso acervo arquitetônico oriundo dos períodos colonial e imperial (MARQUES, 2010).

Pesquisas no perímetro urbano da capital paraense já foram efetuadas no ano de 1989, quando a instituição promoveu uma pesquisa na área da Companhia Docas do Pará. Coordenada por Klaus Hilbert, objetivava descobrir os vestígios da velha fortaleza de São Pedro Nolasco ${ }^{21}$. Ainda nessa fase de florescimento de estudos, os trabalhos também se

\footnotetext{
${ }^{18}$ A Alça Viária do Pará é um complexo de estradas e pontes inaugurada em 2002 visando a interligação da região metropolitana de Belém com municípios do interior do Estado, fazendo parte do Sistema de Integração do Leste Paraense, promovido pelo Governo do Pará. Vale ressaltar que a tese do arqueólogo Fernando Marques, representa uma produção científica associada à pesquisa de contrato. Cf.: Marques (2004) e Pereira (2009).

${ }^{19}$ Coordenado pelo arqueólogo Paulo Roberto do Canto Lopes.

${ }^{20}$ Município localizado na região estuarina amazônica, a um a distância de $60 \mathrm{~km}$ de Belém.

${ }^{21}$ O Forte de São Pedro Nolasco foi erguido a partir de 1665 e situava-se à beira do Rio Guamá, no fundo dos Mosteiros dos Mercedários. Sendo demolido após os conflitos da Cabanagem (1835-1840).
} 
estendiam para outros estados. Já no ano de 1990, o arqueólogo Marcos Magalhães estudou a fortaleza de São José de Macapá, no Amapá (BARRETO, 1992).

No correr dos anos, os arqueólogos do Museu trouxeram à tona novas questões para a história da região.

Investigações foram conduzidas na área onde estava localizada a antiga Igreja de Nossa Senhora do Rosário dos Homens Brancos, que existiu do século XVII até por volta de 1940, sendo encontrada, além de materiais de origem europeia, uma grande quantidade de cerâmica relativa à cultura indígena. (GUAPINDAIA, MARQUES \&MAGALHÃES, 1996).

Em 1995, foram efetivadas pesquisas no prédio do atual Museu de Arte Sacra, onde foram encontrados vestígios do antigo Colégio dos Jesuítas, do início do século XVII, e ainda fragmentos de cerâmica característicos da cultura indígena. De 1997 a 1999, foi realizado um trabalho arqueológico na área do Cais de Belém, onde se localizou os alicerces do Forte de São Pedro Nolasco e do primeiro cais de Belém, além de fragmentos de origem européia associados com peças de cerâmica indígena (MARQUES, 2010).

Situação semelhante ocorreu quando da realização de pesquisas durante o desenvolvimento do Projeto Feliz Lusitânia, quando entre 2001 e 2002 foram feitos estudos arqueológicos da área do Forte do Presépio (do Castelo) e da Casa das Onze Janelas, no centro histórico da cidade. Nas prospecções foram coletados materiais correspondentes à cultura indígena, como cerâmicas não torneadas e artefatos líticos, assim como se verificou a ocorrência de objetos de consumo produzidos na Europa, como pratos e tigelas de faiança e faiança fina, porcelanas, vidros, cachimbos, além de fragmentos de metal como moedas, talheres e itens para uso bélico (MARQUES, 2006).

Em relação ao projeto de restauração do Forte do Castelo, os resultados obtidos tiveram grande relevância a ponto de as descobertas arqueológicas integrarem o programa museológico implantado no local, havendo uma exposição relacionada à estratigrafia do solo, a cultura material indígena e européia coletada, assim como o processo de escavação. A arqueologia teve direta participação no produto final da intervenção no monumento e na proposta de leitura histórica que o mesmo possui na atualidade e que é apresentada ao público. Assim, mais do que um museu militar, o Forte é também um espaço onde são apresentados um pouco sobre o passado indígena amazônico e os contatos culturais que ocorreram na região (COSTA, 2007).

De modo geral, nos exemplos de estudos apontados acima, observa-se que, ainda que direcionadas a darem contas de sítios históricos, as pesquisas no centro histórico belenense 
também apontaram para evidências pré-históricas, as quais não foram desconsideradas pela arqueologia (COSTA, 2007).

A arqueologia urbana também trouxe à tona uma constatação que até então era desconhecida acerca dos processos de contato entre europeus e povos nativos na Baixa Bacia do Amazonas: as primeiras construções de origem européia, estabelecidas no núcleo do que hoje é conhecido como Cidade Velha, foram assentadas sobre antigas aldeias indígenas, ou junto a outras que se situavam nas suas proximidades. Um dado que pode ser explicado por questões estratégicas, envolvendo navegação, defesa e subsistências, mas que também pode estar atrelado às relações que foram estabelecidas com os grupos ameríndios. A grande quantidade de cerâmicas de tradição indígena em comparação aos fragmentos de faianças portuguesas sugere, por exemplo, um comumente consumo da materialidade indígena pelos colonizadores, indicando, por conseguinte, uma maior aproximação entre as comunidades (COELHO e MARQUES, 2011).

Esses são alguns exemplos que ressaltam o potencial arqueológico que os quase quatrocentos anos de história de Belém podem oferecer. Nesse sentido, a arqueologia histórica age como um elemento singular na construção da memória local, dando destaque não somente às chamadas arquiteturas dos “dominantes", mas também resgatando a história dos povos nativos da Amazônia e de que modo se deu o contato entre eles. Ao produzir conhecimento sobre o cotidiano de negros, caboclos e indígenas que habitaram a cidade, cujas trajetórias de vida não aparecem em documentos oficiais, ela torna-se também pública e engajada (FUNARI, 2005).

Não à toa, tal tipo de abordagem arqueológica possibilitou que no Museu Paraense Emílio Goeldi fosse criado uma linha de pesquisa voltada para "arqueologia urbana e resgate da memória da cidade", que fomentou uma série de projetos de restauração no centro histórico de Belém (MARQUES, 2011).

\section{Considerações finais}

O presente texto teve como objetivo traçar um panorama sobre a prática da Arqueologia Histórica no Museu Paraense Emílio Goeldi, considerando os principais objetos de estudo e os resultados que foram obtidos ao longo de quase três décadas de pesquisas em terras amazônicas. Uma ciência relativamente jovem na instituição, cujo florescimento esteve em boa parte atrelada à tradicional arqueologia pré-histórica, já que desde o seu início 
usufruiu de técnicas e metodologias de análise presentes na arqueologia goeldiana desde os tempos de Betty Meggers e Mário Simões ${ }^{22}$.

Assim, como em boa parte do Brasil, a Arqueologia Histórica promovida no Museu Paraense Emílio Goeldi está em processo de desenvolvimento e vem contribuindo para que a instituição também seja reconhecida como um importante centro de investigação da história amazônica. Engenhos coloniais, igrejas, a cultura material européia e indígena são alguns dos principais objetos de investigação no Museu Paraense Emílio Goeldi. A preocupação com o patrimônio histórico e cultural também emerge nos trabalhos realizados, assim como a educação patrimonial realizada em comunidades onde são efetuadas as pesquisas arqueológicas.

Contudo, é pertinente ressaltar que o referido campo de pesquisa ainda tem muito a avançar, precisando se distanciar ainda mais de uma perspectiva meramente descritiva sobre os sítios, estruturas físicas e artefatos, e aproximar-se ainda mais das relações sociais e significados simbólicos inerentes a sociedades pretéritas. Além disso, muitas das pesquisas arqueológicas realizadas nos últimos anos não foram publicadas e encontram-se somente em forma de relatórios técnicos. Essas são questões para as quais os trabalhos futuros devem enveredar.

De todo modo, paralelamente ao estudo das sociedades indígenas do período anterior à colonização, a Arqueologia Histórica vem ganhando espaço no Museu Paraense Emílio Goeldi. Importância que vem sendo conquistada não somente pelo fato de produzir conhecimentos sobre o passado amazônico, mas também por não deixar de estar preocupada com questões atuais inerentes às identidades culturais de várias comunidades.

O que atualmente pode ser observado, portanto, é um processo de construção da prática científica, sendo que os primeiros passos já foram dados e ainda há muito para se investigar.

\section{Referências bibliográficas}

ANDERSON, Scott. "Engenhos na várzea: uma análise do declínio de um sistema de produção tradicional na Amazônia" In: LENA, Philippe; OLIVEIRA, Adélia Engrácia de (Orgs.). Amazônia: a fronteira agrícola 20 anos depois. Belém, $2^{\mathrm{a}}$ edição, Museu Paraense Emílio Goeldi, p. 101-121, 1992.

; MARQUES, Fernando. "Engenhos movidos a maré no estuário do amazonas: vestígios encontrados no município de Igarapé-Miri, Pará” Boletim do Museu Paraense Emílio Goeldi, Belém, vol. 8, nº 2, p. 295-301, 1992.

\footnotetext{
${ }^{22}$ Arqueólogo do Museu Paraense Emílio Goeldi entre 1962 e 1985, atuando como chefe do Setor de Arqueologia da instituição.
} 
BARRETO, Mauro Vianna. "História da pesquisa arqueológica no Museu Paraense Emílio Goeldi” Boletim do Museu Paraense Emílio Goeldi. Belém, vol. 8, nº 2, p. 203-294, 1992.

BINFORD, Lewis. "Archaeology as Antropology" In: American Antiquity, vol. 28, n 2, p 217-225, 1962.

BURKE, Peter. A Escola dos Annales (1929-1989): a Revolução Francesa da historiografia. São Paulo, Unesp, 1997.

CANTO, Otávio do; LOPES, Paulo Roberto do Canto. Novas abordagens em arqueologia preventiva: sítios arqueológicos Bittencourt, Alunorte e Jambuaçu. Belém, Museu Paraense Emílio Goeldi, 2009.

COELHO, Rui Gomes; MARQUES, Fernando. "Processo de contato e primórdios da colonização na baixa bacia do Amazonas (sécs. XVI-XVII). Velhos e Novos Mundos". Congresso Internacional de Arqueologia Moderna, 2011, Lisboa. Anais do Congresso Internacional de Arqueologia Moderna, 2011.

COSTA, Dayseane Ferraz da. Além da pedra e cal: a (re)construção do Forte do Presépio (Belém do Pará, 2000-2004). Dissertação. Programa de Pós-Graduação em História Social da Amazônia, Universidade Federal do Pará, Belém, 2007.

COSTA, Diogo. “Arqueologias Históricas: um panorama espacial e temporal”. Vestígios Revista Latino-americana de Arqueologia Histórica, Belo Horizonte, vol.4, n 2, p.176-200, 2010 .

DEETZ, James. In Small Things Forgotten: The Archeology of Early American Life. New York, Anchor Books, 1977.

FERREIRA, Lúcio Menezes. “'Ordenar o Caos': Emílio Goeldi e a arqueologia amazônica”. Boletim do Museu Paraense Emílio Goeldi. Série Ciências Humanas. Belém, vol.4, n 1 , p.171-190, jan./abr. 2009.

- Território Primitivo: A Institucionalização da Arqueologia no Brasil

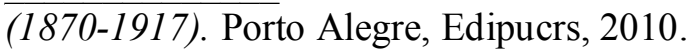

FUNARI, Pedro Paulo. "O Amadurecimento de uma arqueologia histórica mundial". Revista de História, São Paulo, no 135, p. 163-168, jul./dez.1996.

Os avanços da arqueologia histórica no Brasil, um balanço. Com Ciência,

Campinas, 2003. Disponível em: http://www.comciencia.br/reportagens/arqueologia/arq13.shtml. Acesso: 20/12/2012.

- "Teoria e métodos na Arqueologia contemporânea: o contexto da Arqueologia Histórica". Mneme - Revista de Humanidades. Dossiê Arqueologias Brasileiras, Campinas, vol.6, no13, p. 1-5, dez.2004/jan.2005.

. "Teoria e Arqueologia Histórica: A América Latina e o Mundo". Vestígios -

Revista Latino-americana de Arqueologia Histórica, Belo Horizonte, vol.1, nº 1, jul./dez. 2007. 
GUAPINDAIA, Vera Lúcia. Além da margem do rio - as ocupações Konduri e Pocó na região de Trombetas, $P A$. Tese. Programa de pós-graduação em Arqueologia, Universidade de São Paulo, 2008.

GUAPINDAIA, Vera Lúcia; MARQUES, Fernando Luiz Tavares \& MAGALHÃES, Marcos Pereira. "Resgate Arqueológico da Igreja de N. S. do Rosário dos Homens Brancos, em Belém, Pará”. In: Igreja de N. S. do Rosário dos Homens Brancos Séculos XVII/XIX. Belém, Prefeitura Municipal de Belém/FUMBEL (Caminhos da Cultura), 1996.

HALL, Martin; SILLIMAN, Stephen. "Introduction: archaeology of the modern world". In: HALL, Martin; SILLIMAN, Stephen (orgs.). Historical archaeology, Oxford, Blackwell Publishing, p. 1-22, 2006.

JOHNSON, Matthew. Teoría arqueológica: una introducción. Barcelona, Ariel, 2000.

LIMA, Tânia Andrade. "Arqueologia Histórica: algumas considerações teóricas". Clio - Série Arqueológica, Recife, vol.5, p. 87-99, 1989.

“Arqueologia Histórica no Brasil: um balanço bibliográfico (1960-1991)". Anais do Museu Paulista, São Paulo, vol.1, nº1. p. 225-262, 1993.

. "Os marcos teóricos da arqueologia histórica, suas possibilidades e limites". Estudos Ibero-Americanos, Porto Alegre, Edipucrs, vol. 28, nº 2, p. 7-23, 2002.

MARQUES, Fernando Luiz Tavares. Engenhos de Maré em Barcarena, Pará: Arqueologia de seus sistemas Motrizes. Dissertação. Programa de Pós-Graduação em História, Pontifícia Universidade Católica do Rio Grande do Sul, Porto Alegre, 1993.

. "Organização Espacial e Cultura Material no Engenho Murutucu: uma abordagem arqueológica". In: Landi e o Século XVIII na Amazônia, Belém, p. 1-8, 2003.

Modelo da Agroindústria Canavieira Colonial no Estuário Amazônico:

Estudo Arqueológico de Engenhos dos Séculos XVIII e XIX. Tese. Programa de PósGraduação em História, Pontifícia Universidade Católica do Rio Grande do Sul, Porto Alegre, 2004.

- "Investigação arqueológica na Feliz Lusitânia". In: Pará. Secretaria executiva do Estado. (Org.). Feliz Lusitânia/Forte do Presépio - Casa das Onze Janelas Casario da Rua Padre Champagnat. Belém, SECULT-PA, vol.4, p. 147-190, 2006.

- "Um Sítio Indígena sob a Feliz Lusitânia: Descobertas Recentes em Arqueologia Urbana, em Belém do Pará". In: SIMONIAN, Ligia T. L. (Org.). Belém do Pará: História, Cultura e Sociedade. Belém, Editora do NAEA, vol. 1, p. 49-58, 2010.

MEGGERS, Betty; EVANS, Clifford. "Archaelogical investigations at the mouth of the Amazon". Bureau of American Ethnology Bulletin, Washington, vol. 167, p. 1-664, 1957.

ORSER JR., Charles. Introdução à arqueologia histórica. Belo Horizonte, Oficina de Livros, 1992.

PEREIRA, Edith. "O Museu Goeldi e a pesquisa arqueológica: um panorama dos últimos dezessete anos (1991-2008)". Boletim do Museu Paraense Emilio Goeldi. Série Ciências Humanas, Belém, vol.4, nº 1, p.171-190, jan./abr. 2009. 
REIS, José Alberione dos. "Análise do discurso e arqueologia: ...é possível transitar por entremeios?..." Métis: Revista de História e Cultura da Universidade de Caxias do Sul, Caxias do Sul, vol. 1, nº 2, p. 209-228, dez. 2002.

ROOSEVELT, Anna Curtenius. "Arqueologia amazônica". In: CUNHA, Manuela Carneiro da. História dos Índios no Brasil. São Paulo, Companhia das Letras, 1992.

SANJAD, Nelson. A Coruja de Minerva: o Museu Paraense entre o Império e a República (1866-1907). Brasília, Instituto Brasileiro de Museus; Belém, Museu Paraense Emílio Goeldi; Rio de Janeiro, Fundação Oswaldo Cruz, 2010.

"Ciência de potes quebrados: nação e região na arqueologia brasileira do século XIX”. Anais do Museu Paulista, São Paulo, vol. 19, no 1, p. 133-164, 2011.

SYMANSKI, Luís. "Arqueologia Histórica no Brasil: uma revisão dos últimos vinte anos". In: MORALES, Walter F.; MOI, Flavia Prado (orgs.). Cenários Regionais em Arqueologia Brasileira. São Paulo, Annablume, p. 279-310, 2009. 